BD FACSDiva 8.0.1
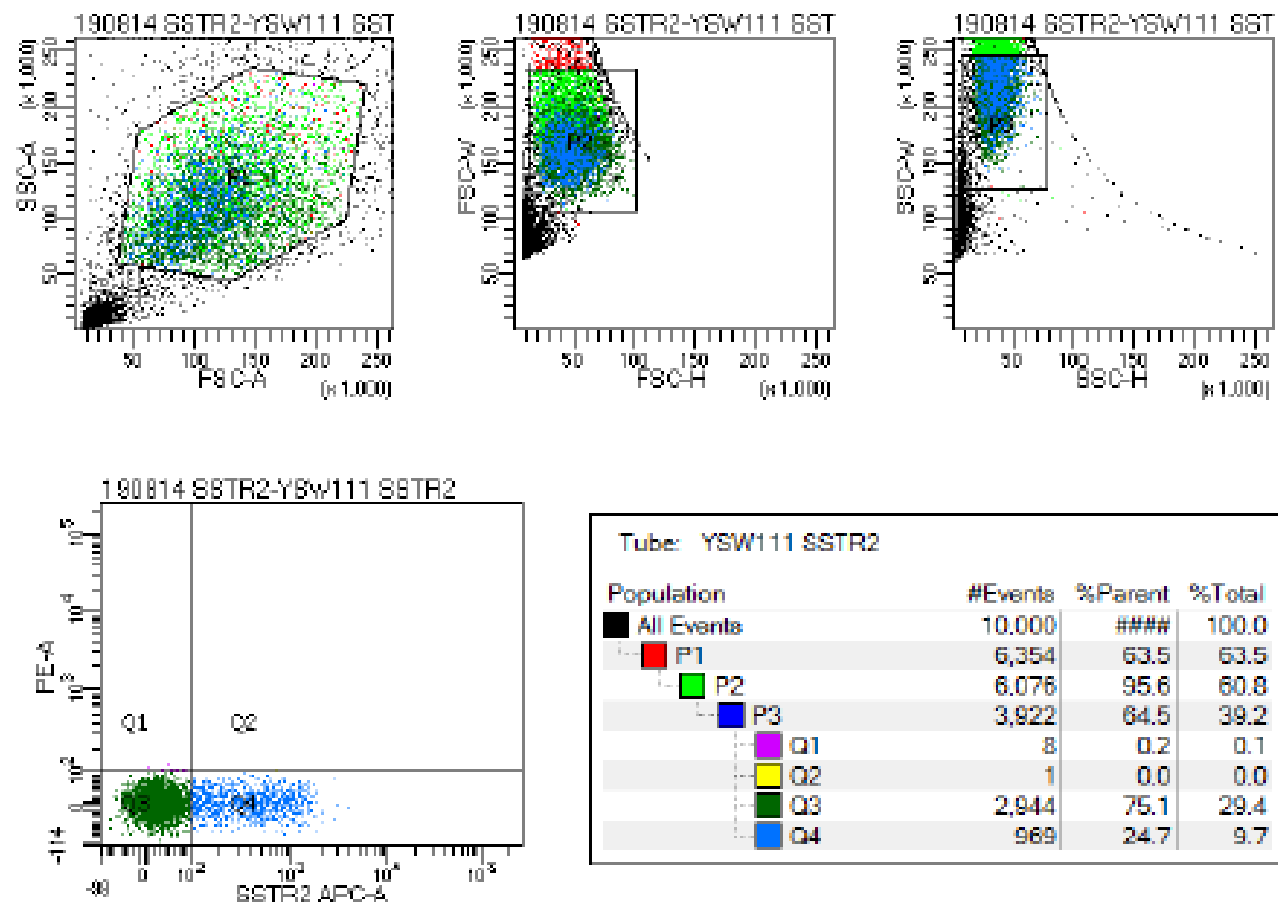

\begin{tabular}{|c|c|c|c|}
\hline Population & \#Events & \%parent & \% Total \\
\hline All Events & 10.000 & \#\#\# & 100.0 \\
\hline P1 & 6,354 & 63.5 & 63.5 \\
\hline$\square$ & 6.076 & 95.6 & 60.8 \\
\hline & 3,922 & 64.5 & 39.2 \\
\hline & 8 & 0.2 & 0.1 \\
\hline & 1 & 0.0 & 0.0 \\
\hline & 2,944 & 75.1 & 29.4 \\
\hline & 969 & 24.7 & 9.7 \\
\hline
\end{tabular}

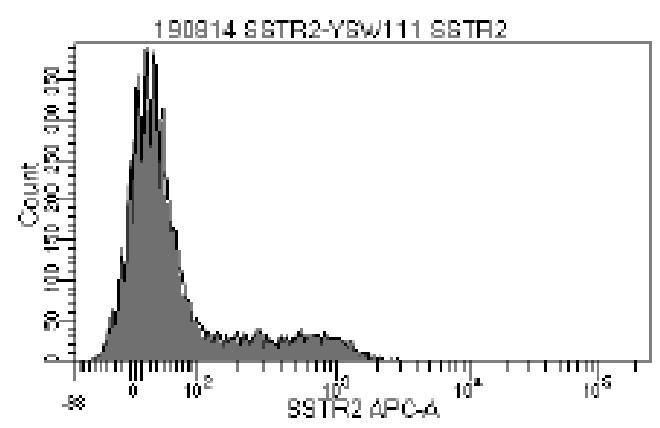




\section{YSW 116}

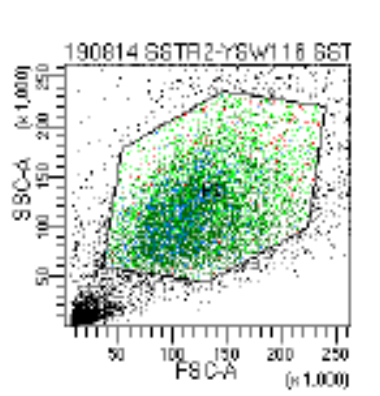

BD FACSDiva 8.0.1
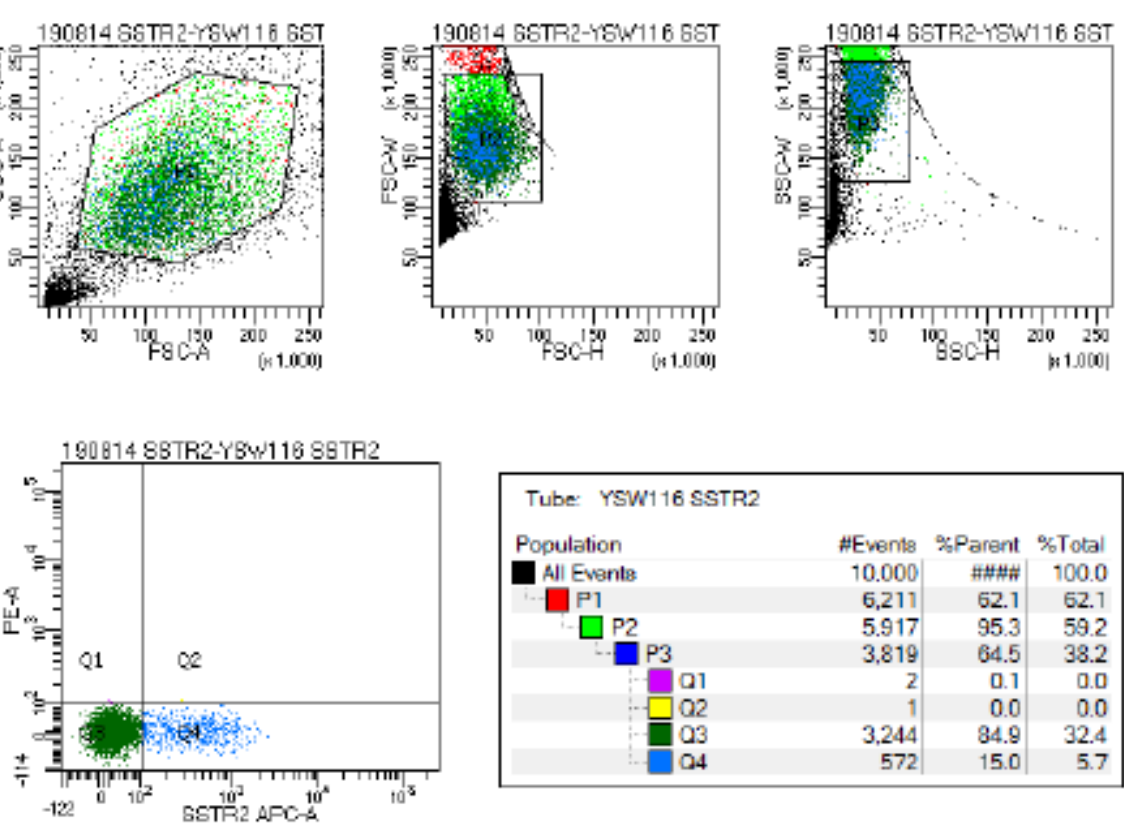

$-122^{\circ} \operatorname{sST}^{10^{2}} \mathrm{AFC}-\Omega^{10^{\circ}}$

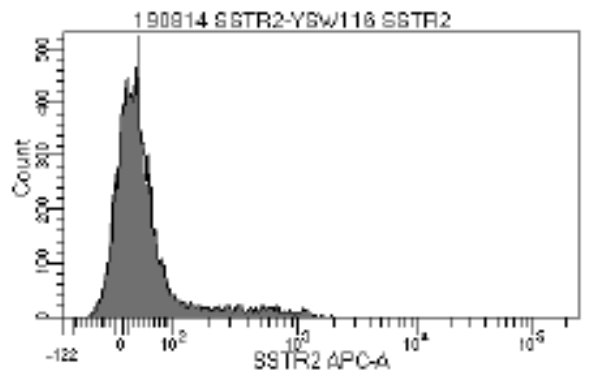




\section{YSW 155}

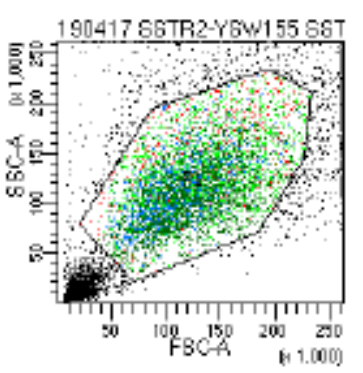

BD FACSDiva 8.0.1
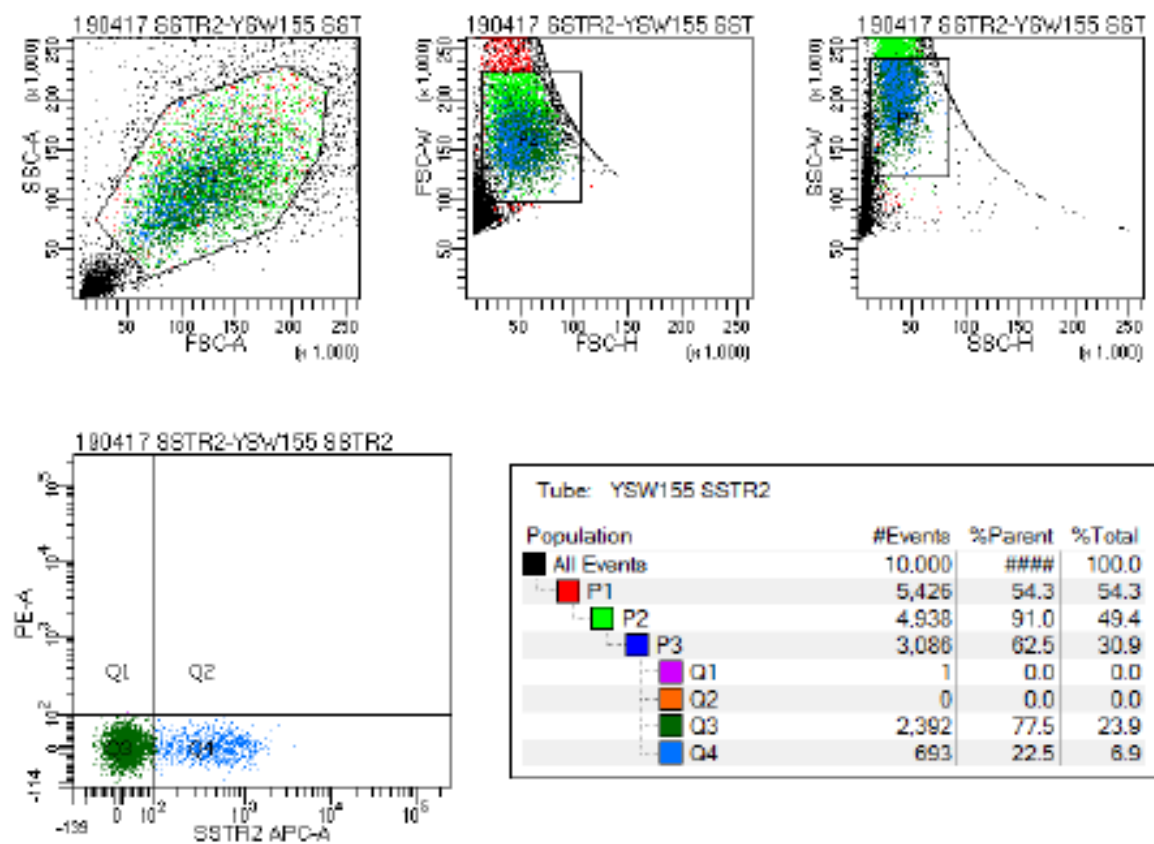

-199 19 SSTH $2 \mathrm{PPCO}$

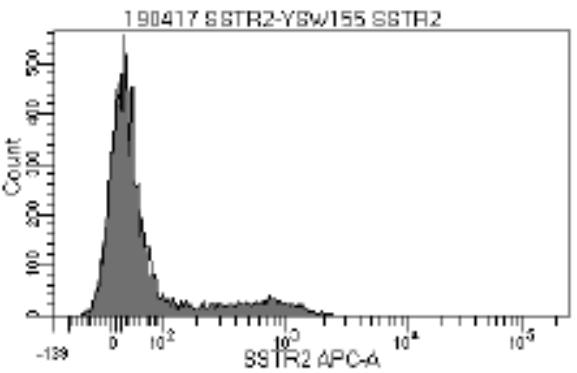


YSW 135

BD FACSDiva 8.0.1
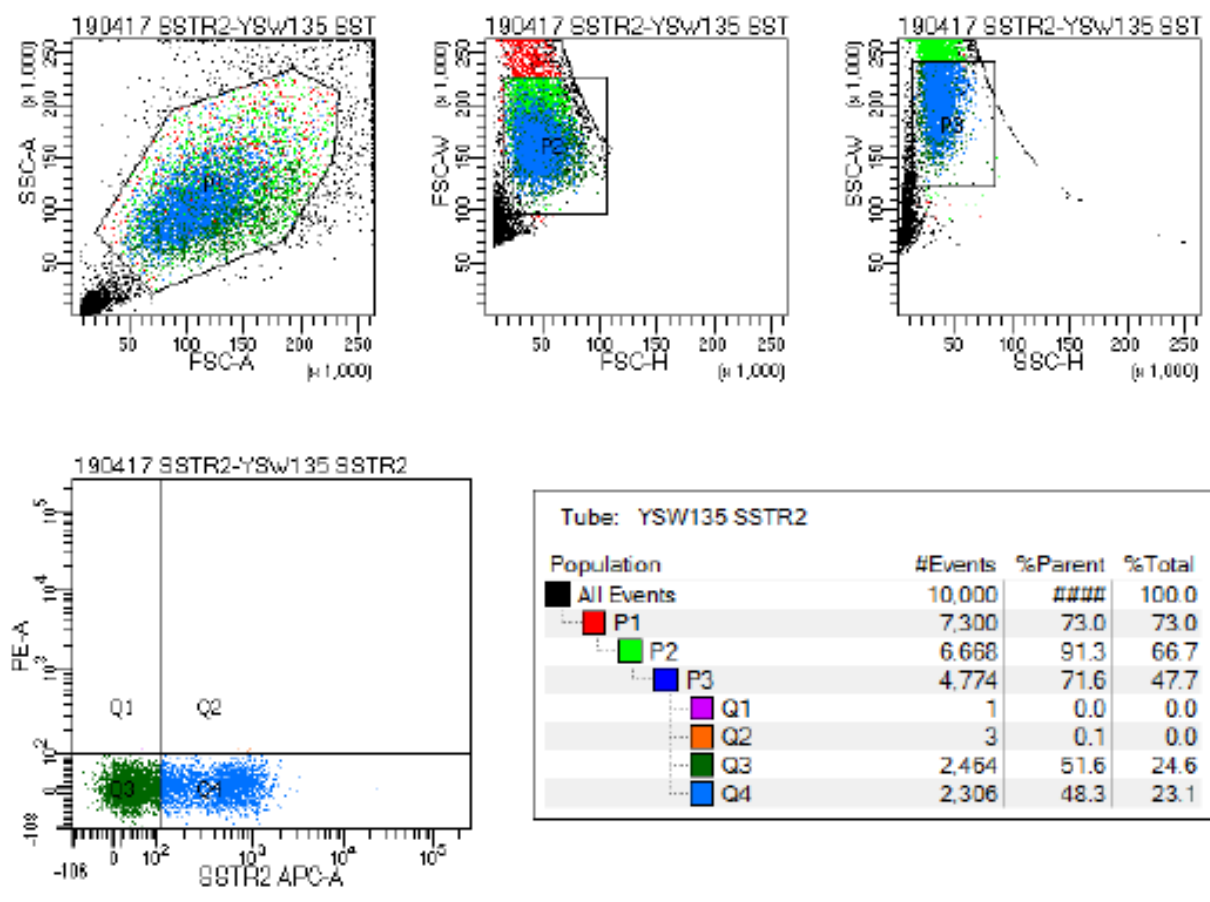

\begin{tabular}{|l|r|r|r|}
\hline Tube: YSW135 SSTR2 & & & \\
Population & HEvents & $\%$ Parent & $\%$ Total \\
\hline All Events & 10,000 & tutnI & 100.0 \\
\hline P1 & 7.300 & 73.0 & 73.0 \\
\hline P2 & 6.668 & 91.3 & 66.7 \\
\hline P3 & 4.774 & 71.6 & 47.7 \\
\hline Q1 & 1 & 0.0 & 0.0 \\
\hline Q2 & 3 & 0.1 & 0.0 \\
\hline Q3 & 2,464 & 51.6 & 24.6 \\
\hline Q4 & 2,306 & 48.3 & 23.1 \\
\hline
\end{tabular}

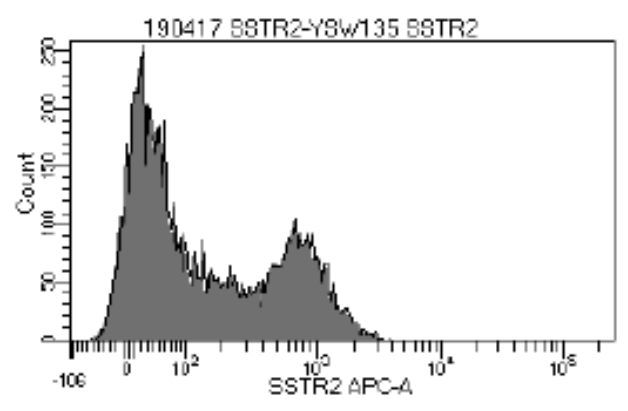




\section{YSW 137}

BD FACSDiva 8.0.1
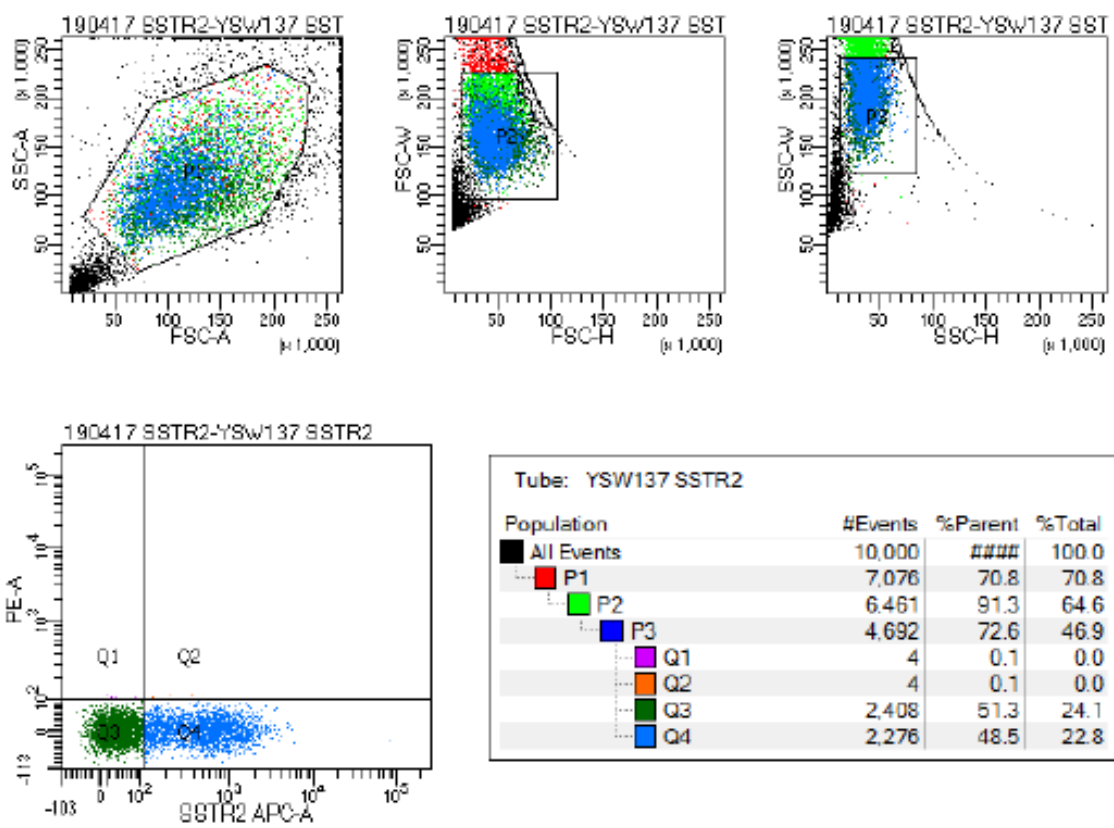

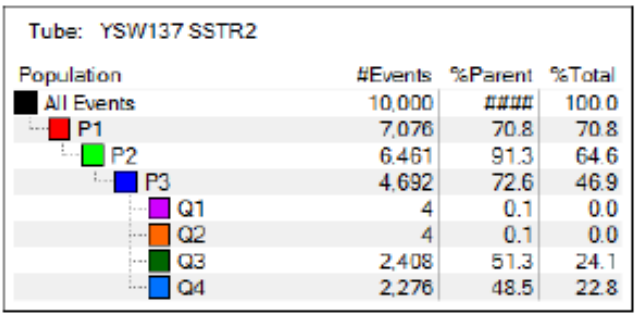

$-103^{\circ} \quad 10^{2} \quad 8 g T^{10} 2 \mathrm{APOA}$

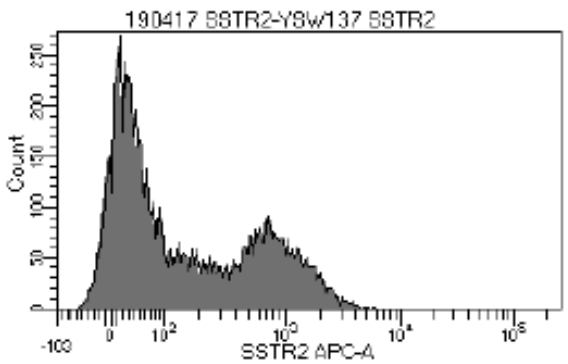



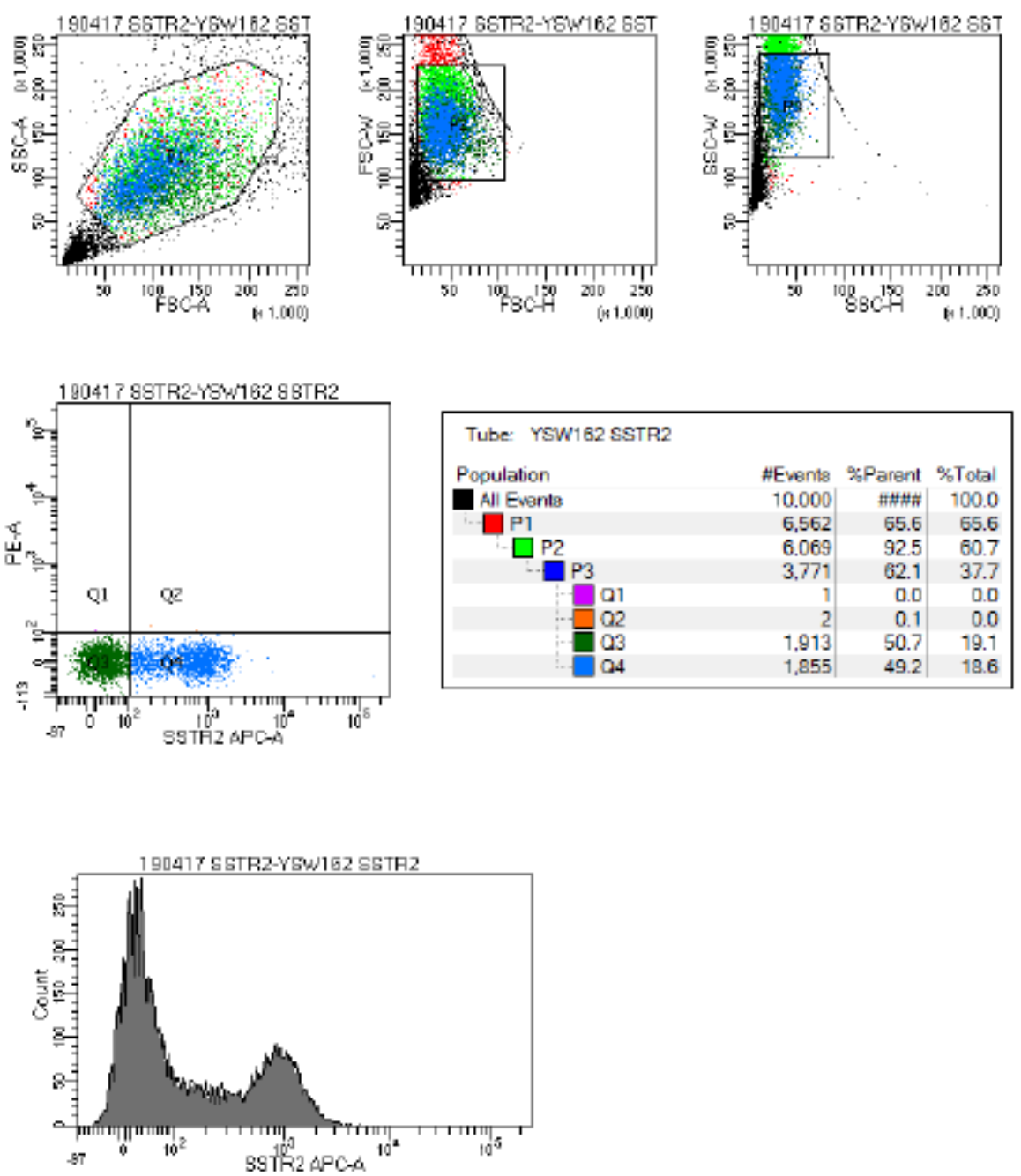